\title{
Acetate-Inducing Metabolic States Enhance Polyhydroxyalkanoate Production in Marine Purple Non-sulfur Bacteria Under Aerobic Conditions
}

\author{
Mieko Higuchi-Takeuchi* and Keiji Numata* \\ Biomacromolecules Research Team, RIKEN Center for Sustainable Resource Science, Saitama, Japan
}

\section{OPEN ACCESS}

Edited by:

Artur M. Cavaco-Paulo, University of Minho, Portugal

Reviewed by: Artur Ribeiro,

Universidade do Minho, Portugal Madalina Tudorache,

University of Bucharest, Romania Adolfo Jose Mota, Federal University of Amazonas, Brazil

*Correspondence: Mieko Higuchi-Takeuchi mieko.higuchi@riken.jp Keiji Numata keiji.numata@riken.jp

Specialty section: This article was submitted to Industrial Biotechnology, a section of the journal Frontiers in Bioengineering and

Biotechnology

Received: 26 February 2019 Accepted: 07 May 2019 Published: 28 May 2019

Citation:

Higuchi-Takeuchi M and Numata K (2019) Acetate-Inducing Metabolic States Enhance Polyhydroxyalkanoate Production in Marine Purple Non-sulfur Bacteria Under Aerobic
Polyhydroxyalkanoates (PHAs) are a family of biopolyesters that a variety of microorganisms accumulate as carbon and energy storage molecules under starvation conditions in the presence of excess carbon. Anoxygenic photosynthetic bacteria exhibit a variety of growth styles and high PHA production activity. Here, we characterized PHA production by four marine purple non-sulfur bacteria strains (Rhodovulum sulfidophilum, Rhodovulum euryhalinum, Rhodovulum imhoffii, and Rhodovulum visakhapatnamense) under different growth conditions. Unlike the well-studied PHA-producing bacteria, nutrient limitation is not appropriate for PHA production in marine purple non-sulfur bacteria. We found that marine purple non-sulfur bacteria did not accumulate PHA under aerobic conditions in the presence of malate and pyruvate. Interestingly, PHA accumulation was observed upon the addition of acetate under aerobic conditions but was not observed upon the addition of reductants, suggesting that an acetate-dependent pathway is involved in PHA accumulation. Gene expression analysis revealed that the expression of isocitrate dehydrogenase in the tricarboxylic acid (TCA) cycle decreased under aerobic conditions and increased with the addition of acetate, indicating that TCA cycle activity is involved in PHA production under aerobic conditions. We also found that expression of PdhR $\mathrm{P}_{\mathrm{rs}}$, which belongs to the GntR family of transcription regulators, in Rhodovulum sulfidophilum was upregulated upon the addition of acetate. Taken together, the results show that the changes in the metabolic state upon the addition of acetate, possibly regulated by PdhR, are important for PHA production under aerobic conditions in marine purple non-sulfur bacteria.

Keywords: polyhydroxyalkanoate, marine purple non-sulfur bacteria, aerobic conditions, TCA cycle, acetate

\section{INTRODUCTION}

Polyhydroxyalkanoates (PHAs) are a family of biopolyesters synthesized by a wide variety of microorganisms as intracellular carbon and energy storage molecules (Lee, 1996a; Rehm, 2003; Nomura and Taguchi, 2007). Recently, PHAs have attracted attention as alternatives to petroleumderived plastics because of their biodegradability and biomass origin (Choi and Lee, 1999; Martina and Hutmacher, 2007). Because PHAs are produced in the presence of excess carbon, the high 
production cost of carbon sources such as plant oils and sugars is one of the most important issues associated with PHA production. The use of photosynthetic organisms to produce materials is a potential method for reducing PHA production costs. Many studies have focused on higher plants and cyanobacteria as PHA producers that directly utilize carbon dioxide $\left(\mathrm{CO}_{2}\right)$ (Mittendorf et al., 1998; Mooney, 2009; Osanai et al., 2013).

Anoxygenic photosynthetic bacteria, especially purple nonsulfur bacteria, are known to produce PHA at high levels (Liebergesell et al., 1991; Higuchi-Takeuchi et al., 2016) and have nitrogen fixation as well as $\mathrm{CO}_{2}$ fixation abilities (Tabita, 1995; Joshi and Tabita, 1996; McKinlay and Harwood, 2010). Purple non-sulfur bacteria perform three important biological reactions that sustain almost all organisms: light energy conversion, $\mathrm{CO}_{2}$ fixation and nitrogen fixation. Therefore, the utilization of purple non-sulfur bacteria is an environmentally friendly method for the production of useful materials. According to a study on the life cycle assessment (LCA) of PHA (Akiyama et al., 2003), we can reduce the cost of carbon and nitrogen sources for cultivation using their photosynthesis and nitrogen fixation abilities if we use marine purple non-sulfur bacteria as a host for PHA production. Purple non-sulfur bacteria exhibit a wide range of growth modes. A majority of purple non-sulfur bacteria can grow as photoautotrophs or photoheterotrophs in light, and some strains can grow aerobically in the dark as chemoheterotrophs. This variety of growth modes offers possibilities for a wide range of applications. Many application-based studies, such as studies on hydrogen production, vitamin production and bioremediation, have been carried out using anoxygenic photosynthetic bacteria (Sasikala and Ramana, 1995; Levin et al., 2004; Idi et al., 2015).

We focused on marine purple photosynthetic bacteria because high salinity can reduce the risk of biological contamination; and seawater, which is highly abundant and a low cost medium, can be used as a growth medium. Although PHA production by purple non-sulfur bacteria has been studied using freshwater strains of Rhodospirillum rubrum (Clemente et al., 2000) and Rhodobacter sphaeroides (Brandl et al., 1991), little is known about PHA production in marine purple photosynthetic bacteria. In our previous study, we demonstrated that marine purple non-sulfur bacteria were able to produce PHA under nutrientrich growth conditions, unlike other well-known PHA-producing bacteria, which require nutrient-limited conditions (HiguchiTakeuchi et al., 2016). We also revealed that the properties of the PHA synthase $\left(\mathrm{PhaC}_{\mathrm{Rs}}\right)$ from Rhodovulum sulfidophilum, a marine purple non-sulfur bacterium, are quite different from those of well-known PhaC proteins (Higuchi-Takeuchi et al., 2017). PhaC $C_{R s}$ exists predominantly as an active dimer even in the absence of substrate, and $\mathrm{PhaC}_{\mathrm{Rs}}$ activity increased with increasing substrate concentration.

In the present study, we examined PHA production by marine purple non-sulfur bacteria grown under different light and oxygen conditions. We found that PHA production was dependent on cell growth in the case of marine purple nonsulfur bacteria, unlike the PHA production observed in wellknown PHA-producing bacteria. The marine purple non-sulfur bacteria did not accumulate PHA under aerobic conditions in the presence of malate and pyruvate, whereas PHA accumulation was greatly induced by the addition of acetate. Expression analysis suggested that tricarboxylic acid (TCA) cycle activity and expression of the GntR family of transcription regulators were involved in the enhancement of PHA production by the addition of acetate under aerobic conditions in $R$. sulfidophilum.

\section{MATERIALS AND METHODS Culture Conditions}

The marine purple non-sulfur bacteria investigated in this study were obtained from the biological resource centers (RIKEN BioResource Center, DSMZ, and ATCC) listed in Table S1. The marine purple non-sulfur bacteria were cultured in growth medium containing the following components per liter: $\mathrm{KH}_{2} \mathrm{PO}_{4}, 0.5 \mathrm{~g} ; \mathrm{CaCl}_{2} \cdot 2 \mathrm{H}_{2} \mathrm{O}, 0.25 \mathrm{~g} ; \mathrm{MgSO}_{4} \cdot 7 \mathrm{H}_{2} \mathrm{O}, 3.0 \mathrm{~g}$; $\mathrm{NH}_{4} \mathrm{Cl}, 0.68 \mathrm{~g} ; \mathrm{NaCl}, 20 \mathrm{~g}$; sodium malate, $3.0 \mathrm{~g}$; sodium pyruvate, $3.0 \mathrm{~g}$; yeast extract, $0.4 \mathrm{~g}$; ferric citrate, $0.25 \mathrm{mg}$; vitamin $\mathrm{B} 12$, $2 \mathrm{mg} ; \mathrm{ZnCl}_{2} \cdot 5 \mathrm{H}_{2} \mathrm{O}, 70 \mu \mathrm{g} ; \mathrm{MnCl}_{2} \cdot 4 \mathrm{H}_{2} \mathrm{O}, 100 \mu \mathrm{g} ; \mathrm{H}_{3} \mathrm{BO}_{3}, 60 \mu \mathrm{g}$; $\mathrm{CoCl}_{2} \cdot 6 \mathrm{H}_{2} \mathrm{O}, 200 \mu \mathrm{g} ; \mathrm{CuCl}_{2} \cdot 2 \mathrm{H}_{2} \mathrm{O}, 20 \mu \mathrm{g} ; \mathrm{NiCl}_{2} \cdot 6 \mathrm{H}_{2} \mathrm{O}, 20 \mu \mathrm{g}$; and $\mathrm{Na}_{2} \mathrm{MoO}_{4} \cdot \mathrm{H}_{2} \mathrm{O}, 40 \mu \mathrm{g}$. The $\mathrm{pH}$ was adjusted to 6.8 with $5 \mathrm{M}$ of $\mathrm{NaOH}$. The photosynthetic purple bacteria were grown under continuous far-red LED light conditions, as described below, at $30^{\circ} \mathrm{C}$ in screw-capped glass tubes, vials or plastic tubes.

\section{Nutrient-Limited Culture Conditions}

For the nitrogen-limited conditions, $\mathrm{NH}_{4} \mathrm{Cl}$, sodium malate and sodium pyruvate were removed from the growth medium, and $5 \mathrm{~g}$ of sodium acetate per liter was added as a carbon source. For phosphate-limited conditions, $\mathrm{KH}_{2} \mathrm{PO}_{4}$ was removed from the growth medium and supplemented with $0.28 \mathrm{~g}$ of $\mathrm{KCl}$, and $5 \mathrm{~g}$ of sodium acetate per liter was added as a carbon source. The photosynthetic purple bacterial cells were cultured in growth medium and harvested during the log phase $\left(\mathrm{OD}_{660}=\sim 2.0\right)$ and then washed with nitrogen or phosphate-limited medium. The washed cells were diluted to a starting $\mathrm{OD}_{660}$ of 0.1 in nitrogenor phosphate-limited medium. Screw-capped glass tubes were filled with medium to the tops of the necks and cultured at $30^{\circ} \mathrm{C}$ with agitation under $8 \mathrm{~W} / \mathrm{m}^{2}$ of $730-\mathrm{nm}$ LED light.

For vitamin-free conditions, vitamin B12, yeast extract, sodium malate and sodium pyruvate were removed from the growth medium, and $5 \mathrm{~g}$ of sodium acetate per liter was added as a carbon source. Cells were cultured in growth medium and harvested in the late log phase $\left(\mathrm{OD}_{660}=\sim 2.0-3.0\right)$. Harvested cells were washed with vitamin-free medium two times. For the two-stage culture method, cell cultures were diluted to a starting $\mathrm{OD}_{660}$ of 1.0 with and without vitamin $\operatorname{mix}(1 \mathrm{mg} / \mathrm{L}$ thiamine, $1 \mathrm{mg} / \mathrm{L}$ nicotinic acid, $0.6 \mathrm{mg} / \mathrm{L}$ 4-aminobenzoic acid, $0.1 \mathrm{mg} / \mathrm{L}$ biotin, $2 \mathrm{mg} / \mathrm{L}$ vitamin $\mathrm{B}_{12}$ ) and cultured at $30^{\circ} \mathrm{C}$ under $8 \mathrm{~W} / \mathrm{m}^{2}$ of 730-nm LED light in screw-capped glass tubes filled with medium with agitation for 2 days.

\section{Growth Light Conditions}

LED lights with wavelengths of $730 \mathrm{~nm}$ (VBP-L24-C3, Valore, Tokyo, Japan), $800 \mathrm{~nm}$ (ISC-201-2, CCS, Kyoto, Japan) and 850 nm (LFX2-200IR850, Marubishi Bioengineering, Tokyo, Japan) were used as light sources at the indicated intensities. Cells 
were cultured in growth medium and harvested during the log phase $\left(\mathrm{OD}_{660}=\sim 2.0\right)$. The harvested cells were diluted to a starting $\mathrm{OD}_{660}$ of 0.1 and cultured for 1 to 4 days at $30^{\circ} \mathrm{C}$ in a $15-\mathrm{ml}$ plastic tube filled with medium to the top of the neck of the tube without agitation.

\section{Aerobic and Anaerobic Culture Conditions}

The $25 \mathrm{ml}$ glass vials were used under different oxygen concentrations in Figure 3A. Under aerobic conditions, $7 \mathrm{ml}$ of $\log$ phase cells were cultured at $30^{\circ} \mathrm{C}$ in the dark using $25-\mathrm{ml}$ vials with silicon plugs with shaking at $180 \mathrm{rpm}$. For oxygenlimited conditions, screw-capped vials were filled with medium to the tops of the necks. For anaerobic conditions, $10 \mathrm{ml}$ of cell culture was added to $25-\mathrm{ml}$ vials, and nitrogen gas was bubbled for $10 \mathrm{~min}$. For all the conditions, the cells were diluted to a starting $\mathrm{OD}_{660}$ of 0.1 and cultured in growth medium at $30^{\circ} \mathrm{C}$ for 2 days.

For the aerobic cultures in Figures 3B, 4, cells were cultured in the growth medium and harvested during the log phase $\left(\mathrm{OD}_{660}=\sim 2.0\right)$. Fifty milliliters of log phase cells were cultured at $30^{\circ} \mathrm{C}$ in the dark using 200 -ml flasks with silicon plugs with shaking at $180 \mathrm{rpm}$. The harvested cells were diluted to a starting $\mathrm{OD}_{660}$ of 0.1 and cultured for 2 days. For PHA production under aerobic conditions in the presence of chemicals, cells were cultured with $10 \mathrm{mM}$ dimethyl sulfide (DMS), $10 \mathrm{mM}$ trimethylamine (TMA) and $10 \mathrm{mM}$ thiosulfate, and $20 \mathrm{mM}$ sodium bicarbonate, $0.5 \%$ sodium succinate and $0.5 \%$ sodium acetate.

\section{Analysis of PHA Content}

The method used for PHA content characterization was modified slightly from a previous study (Chuah et al., 2013). The DCWs of lyophilized cells were determined gravimetrically. Approximately $0.5-2 \mathrm{mg}$ of lyophilized cells was subjected to methanolysis in the presence of $1,000 \mu \mathrm{l}$ of chloroform, $150 \mu \mathrm{l}$ of sulfonic acid and $850 \mu \mathrm{l}$ of methanol at $100^{\circ} \mathrm{C}$ for $140 \mathrm{~min}$. After cooling, phosphate buffer ( $\mathrm{pH}$ 8.1) was added to the reaction mixture, which was then neutralized with $5 \mathrm{~N} \mathrm{NaOH}$. After centrifugation at $1,500 \mathrm{rpm}$ for $5 \mathrm{~min}$, the bottom chloroform layer was dried over anhydrous sodium sulfate. The PHA content was determined using a gas chromatography-mass spectrometry (GC-MS) apparatus (GCMS-QP2010 Ultra, Shimadzu, Kyoto, Japan) equipped with a $30 \mathrm{~m} \times 0.25 \mathrm{~mm}$ DB-1 capillary gas chromatography column (Agilent Technologies, CA, USA). For analysis, a $1-\mu \mathrm{l}$ volume of sample solution was injected with helium as a carrier gas $\left(3.30 \mathrm{ml} \mathrm{min}^{-1}\right)$. The following temperature program was used to separate methyl esters: $45^{\circ} \mathrm{C}$ for $1 \mathrm{~min}$, followed by a temperature ramp of $7^{\circ} \mathrm{C}$ per min to $117^{\circ} \mathrm{C}$. The interface and ion source temperatures were $250^{\circ} \mathrm{C}$ and $230^{\circ} \mathrm{C}$, respectively. The $3 \mathrm{HB}$ content was determined using a calibration curve.

\section{Quantitative Reverse Transcription Polymerase Chain Reaction (RT-PCR) Analysis}

Under aerobic conditions, cells were cultured in growth medium and harvested during the $\log$ phase $\left(\mathrm{OD}_{660}=\sim 2.0\right)$. The harvested cells were diluted to a starting $\mathrm{OD}_{660}$ of 0.1 and cultured using 200-ml flasks with shaking in the dark for 2 days. Cells were also cultured under aerobic conditions in the presence of $5 \mathrm{~g}$ of sodium acetate per liter for 2 days. Under anaerobic conditions, log-phase cells were transferred to $15-\mathrm{ml}$ plastic tubes and nitrogen gas was bubbled for $10 \mathrm{~min}$ and cultured under farred light $\left(30 \mathrm{~W} / \mathrm{m}^{2}: 730 \mathrm{~nm}\right)$ for 2 days. For different growth light intensity conditions, cells were cultured in $15-\mathrm{ml}$ plastic tubes filled with medium to the top of the neck of the tube without agitation in low $\left(8 \mathrm{~W} / \mathrm{m}^{2}: 800 \mathrm{~nm}\right)$ and high $\left(50 \mathrm{~W} / \mathrm{m}^{2}: 800 \mathrm{~nm}\right)$ light for 3 days. All cells were frozen by liquid nitrogen and stored at $-80^{\circ} \mathrm{C}$ until use.

Total RNA was extracted from $R$. sulfidophilum cells using the RNAeasy Mini Kit (Qiagen, Tokyo, Japan). Using 0.1 to $1.0 \mu \mathrm{g}$ of RNA as a template, cDNA was synthesized by the QuantiTect Reverse Transcription Kit (Qiagen, Hilden, Germany) following the manufacturer's protocol. Quantitative reverse transcription PCR (RT-PCR) was performed using SsoAdvancedTM Universal SYBR Green Supermix (BIO-RAD, Hercules, CA, USA). The real-time RT-PCR analysis was performed by StepOne (ThermoFisher Scientific, Waltham, MA, USA) according to the manufacturer's protocol. The PCR conditions were composed of an initial denaturation step at $95^{\circ} \mathrm{C}$ for $10 \mathrm{~min}, 40 \mathrm{cycles}$ at $95^{\circ} \mathrm{C}$ for $15 \mathrm{sec}$, and $60^{\circ} \mathrm{C}$ for $15 \mathrm{sec}$.

Melting curves were generated after amplification. The primer sets used to determine expression levels were designed by GENETYX Ver.13 and shown in Table S2. The specificities of primers were evaluated by melting curve analyses. Efficiencies were estimated from standard curves based on two-fold dilutions. The relative quantification in gene expression was determined using the standard curve method. Three to four biological replicates and four technical replicates of each biological replicate were used. The $r p o D$ gene was used as a housekeeping gene to normalize the expression levels of target genes.

\section{Statistical Analysis}

Statistically significant differences between groups were determined by the Student $t$-test, where a $p<0.05$ indicated a significant difference.

\section{RESULTS AND DISCUSSION}

\section{Nutrient Limitation for PHA Production}

PHA is known to be accumulated when excess carbon is present and other nutrients, such as nitrogen, phosphorus and sulfur, are limited (Valappil et al., 2008). In the case of marine purple non-sulfur bacteria, it was reported that PHA production was induced under nitrogen-limited (Liebergesell et al., 1991) or vitamin-limited conditions (Chowdhury et al., 1996). However, our previous study demonstrated that PHA production in some marine purple non-sulfur bacterial strains was not enhanced under nitrogen-limited conditions (Higuchi-Takeuchi et al., 2016). Time-course analysis of PHA contents (wt\%) was performed using four marine purple non-sulfur bacterial strains (Table S1, R. sulfidophilum, R. euryhalinum, R. imhoffi and $R$. visakhapatnamense) under nitrogen-limited conditions and compared with under nutrient-rich conditions (Figure S1). 
PHA contents between 1 day and 5 days of cultivation were compared both under nutrient-rich and nitrogen-limited conditions in four strains. Significant differences were found under nutrient-rich conditions in all strains ( $R$. sulfidophilum; $p=0.002, R$. euryhalinum; $p=0.025, R$. imhoffi $; p=0.010$, $R$. visakhapatnamense; $p=0.007)$. On the other hand, there were no statistically significant differences under nitrogenlimited conditions ( $R$. sulfidophilum; $p=0.053$, R. euryhalinum; $p=0.253, R$. imhoffi; $p=0.203, R$. visakhapatnamense; $p=0.172)$. These results indicate that the PHA content per dry cell weight $(w t \%)$ did not increase during the incubation period under nitrogen-limited conditions, whereas a slight increase was observed for all the strains under nutrient-rich conditions. R. sulfidophilum showed higher PHA production after 5 days of incubation compared to other strains. We previously reported PHA production after 7 days of incubation using 9 purple non-sulfur bacteria strains (Higuchi-Takeuchi et al., 2016) and $R$. visakhapatnamense showed the highest PHA production and $R$. sulfidophilum exhibited the second highest PHA production. As shown in Figure S1, PHA production of $R$. sulfidophilum decreased after 6 days, whereas PHA production of R. visakhapatnamense increased gradually, leading to high PHA production of $R$. sulfidophilum after 5 days of incubation.

The PHA content of the four strains was examined under phosphate-limited conditions (dark gray bars in Figure 1A). R. sulfidophilum exhibited higher PHA content (53.9 wt\%) under phosphate-limited conditions than under nutrient-rich conditions. $R$. visakhapatnamense produced comparable PHA content (31.3 wt\%) under phosphate-limited conditions and nutrient-rich conditions (31.3 wt $\%$ ). These results suggest that PHA production is induced by phosphate limitation. However, all four strains grew poorly under phosphate-limited conditions because the extreme nutrient limitation caused poor cell growth and consequently reduced the total PHA production. As shown in Figure 1B, the PHA concentrations $(\mathrm{mg} / \mathrm{L}$ of culture) were higher in the nutrient-rich medium than in the phosphatelimited medium.

It has been reported that $R$. sulfidophilum accumulates PHA under vitamin-free conditions (Chowdhury et al., 1996). Next, we examined bacterial growth in the absence of vitamins. Vitamin B12 and yeast extract, which contains high levels of B vitamins, were removed from the growth medium, and four strains were inoculated at an initial $\mathrm{OD}_{660}$ of 0.1 in the vitamin-free medium (lacking vitamin B12 and yeast extract). The PHA content could not be determined under these conditions due to poor growth of the marine purple non-sulfur bacteria. Therefore, we used a two-stage culture method for PHA production. In this method, PHA production was induced with improved productivity after sufficient cell growth was achieved. Bacterial cells were cultured at a starting $\mathrm{OD}_{660}$ of 1.0 in vitamin-free or vitamin-sufficient medium for 2 days, and the PHA content was measured. The PHA content of all four strains was not significantly different between vitamin-free and vitamin-sufficient conditions (Figure 1C). These results indicate that PHA production was not enhanced by vitamin-free conditions in the marine purple non-sulfur bacteria.

\section{Growth Dependent PHA Production}

As shown in Figure S1, PHA production appeared to be dependent on cell growth. Purple non-sulfur bacteria use far-red light energy via bacteriochlorophyll absorption for growth, and hence, we examined the effect of light quality and light intensity on cell growth and PHA production. Cell growth and PHA production were examined using far-red LEDs at three different wavelengths $(730,800$ and $850 \mathrm{~nm})$ with $R$. sulfidophilum as a representative strain of marine purple non-sulfur bacteria. As shown in Figure 2A, the $R$. sulfidophilum cells grew well for up to 4 days of cultivation under illumination with LEDs at $800 \mathrm{~nm}$ (black triangles) and $850 \mathrm{~nm}$ (black squares), in contrast to growth under a 730-nm LED (black circles). This observation is plausible, because the absorption spectra of $R$. sulfidophilum exhibited peaks at 800 and $850 \mathrm{~nm}$ (Masuda et al., 1999), whereas 730 -nm LED lighting was the best for bacterial growth after 5 days of cultivation. Generally, the penetration of light into photosynthetic microorganisms is limited at high cell densities because of the mutual shading of cells, and short-wavelength light can penetrate deeper than long-wavelength light. It is reported that short wavelengths of light $(600-780 \mathrm{~nm})$ reached the deeper part of the bioreactor, and energy of long wavelength light (800$850 \mathrm{~nm}$ ) was lost in $R$. sphaeroides (Nakada et al., 1995). These results imply that short-wavelength LED lights $(730 \mathrm{~nm})$ might be able to penetrate the cells even at high cell densities.

Next, we examined the effects of light intensity on PHA production using LEDs of three different wavelengths in $R$. sulfidophilum (Figure 2B). Under all the conditions, the PHA concentrations $(\mathrm{mg} / \mathrm{L})$ increased with increasing incubation time. The PHA concentrations were highest after 4 days of cultivation $(1.2 \mathrm{~g} / \mathrm{L})$ under low-light conditions with $800-\mathrm{nm}$ LED lighting. The PHA content (wt\%) was compared to dry cell weight (DCW) (mg/L) under low-light and high-light conditions with 800-nm LED lighting (Figure 2C). The DCWs were lower (or comparable) under low-light conditions than under highlight conditions. $R$. sulfidophilum exhibited higher PHA content (17-50 wt\%) under low-light conditions than under high-light conditions (15-30 wt\%), leading to the high PHA concentrations under low-light conditions shown in Figure 2B. The PHA content under low-light conditions with the three LED lights was plotted against the DCWs (Figure S2A). A linear correlation between PHA content and DCW was observed under low-light conditions $\left(R^{2}=0.6289\right)$, indicating that PHA production is dependent on cell growth under low-light conditions. On the other hand, the correlation coefficient between PHA content and DCW under high-light conditions was quite low $\left(R^{2}=0.0028\right.$, Figure S2B $)$, indicating that there was no linear relationship. As shown in Figure 2C, the DCWs did not increase under high-light conditions during cultivation. Low PHA production under high-light conditions might be caused by poor cell growth.

PHA-producing bacteria can be divided into two groups based on culture conditions (Lee, 1996b). The first group requires nutrient limitation for PHA production. Cupriavidus necator, which is the most widely studied PHA producer, and many other bacteria belong to this group. The second group of bacteria does not require nutrient limitation and can accumulate PHA 

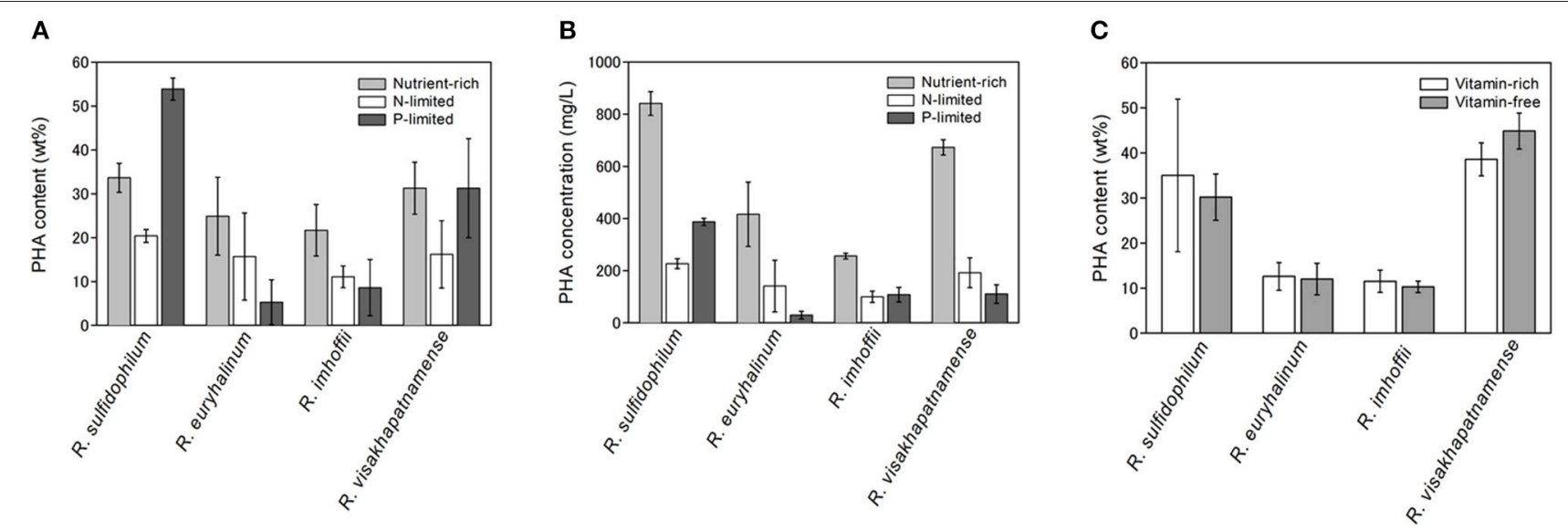

FIGURE 1 | PHA production under nutrient limited conditions. (A) PHA content (wt\%) and (B) PHA concentrations (mg/L) under nutrient-rich and nutrient-limited conditions. Four marine purple non-sulfur bacterial strains ( $R$. sulfidophilum, $R$. euryhalinum, $R$. imhoffii and $R$. visakhapatnamense) were cultured in growth medium and then inoculated in nitrogen-limited (white bars) or phosphate-limited (dark gray bars) medium supplemented with $0.5 \%$ sodium acetate and in growth medium (light gray bars). (C) PHA content (wt\%) under vitamin-free (light gray bars) and vitamin-rich (white bars) conditions. Data are the mean \pm SD of at least three cultures.

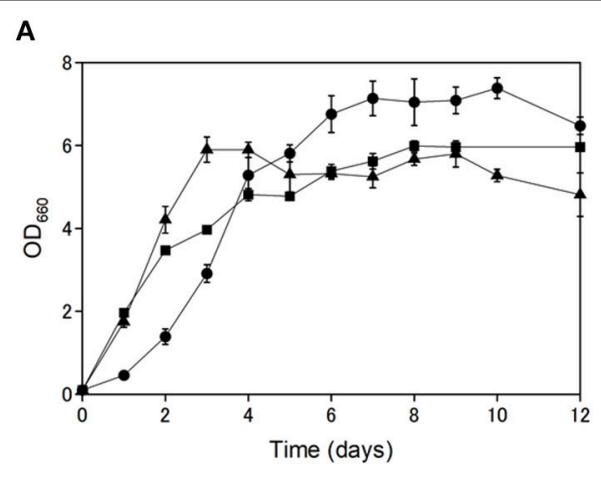

C

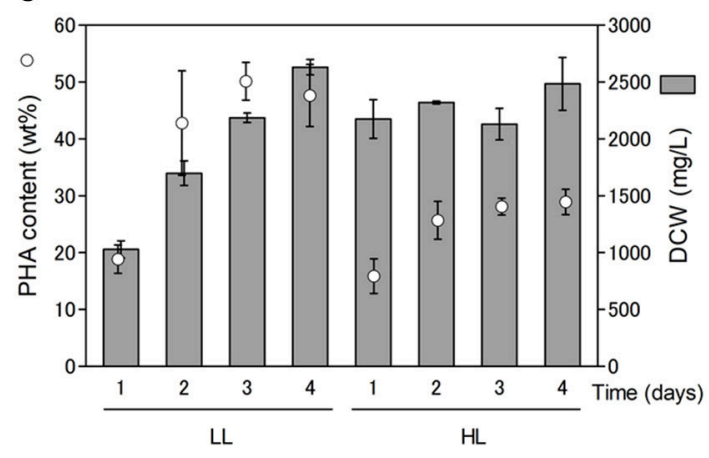

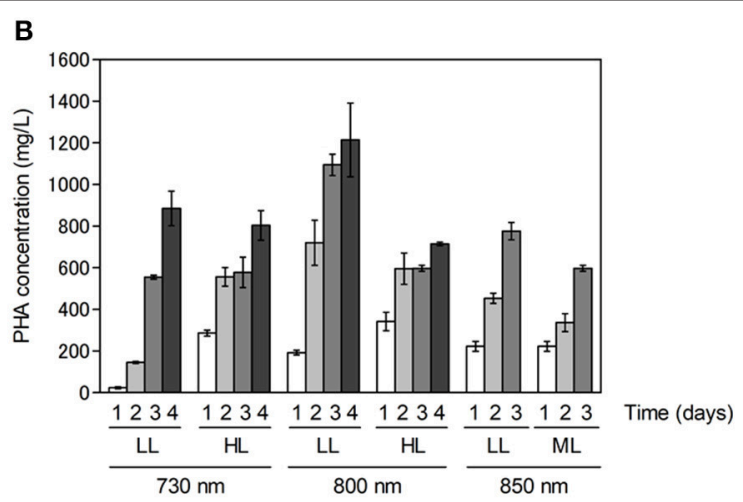

D

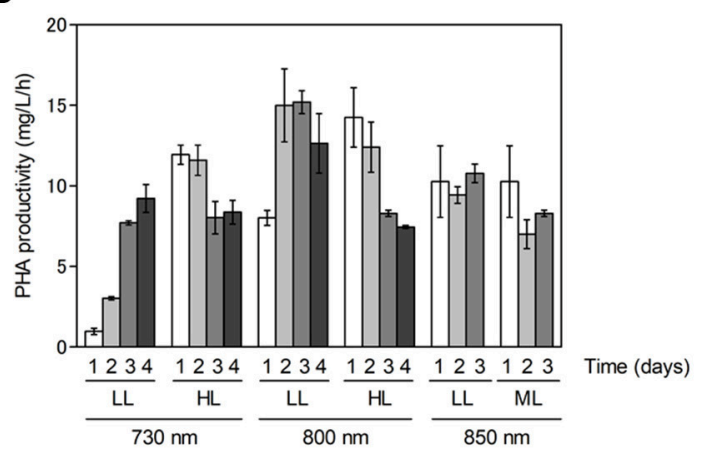

FIGURE 2 | Cell growth and PHA production under different light conditions. (A) Growth of marine purple non-sulfur bacteria under different light conditions. Cells were inoculated in growth medium to an $\mathrm{OD}_{660}$ of 0.1 and cultured for 1 to 12 days under $8 \mathrm{~W} / \mathrm{m}^{2}$ of 730 -nm (black circles), 800 -nm (black triangles) and 850 -nm (black squares) LEDs. Data are the mean \pm SD of at least three cultures. (B) PHA concentrations (mg/L) under different light conditions. Cells were cultured under low-light (LL: $\left.8 \mathrm{~W} / \mathrm{m}^{2}\right)$, intermediate-light (ML: $\left.20 \mathrm{~W} / \mathrm{m}^{2}, 850 \mathrm{~nm}\right)$ and high-light $\left(\mathrm{HL}: 50 \mathrm{~W} / \mathrm{m}^{2}\right)$ conditions. PHA concentrations were determined after 1 to 4 days of incubation. Data are the mean \pm SD of at least three cultures. (C) Comparison between PHA content and DCW under 800-nm LED lighting. PHA content under low and high intensities of 800-nm LED light were plotted against DCWs. PHA contents and DCWs were determined after 1 to 4 days of incubation. (D) Time-course of PHA productivity (mg/L/h) under different light conditions. PHA productivities were determined after 1 to 4 days of incubation. 


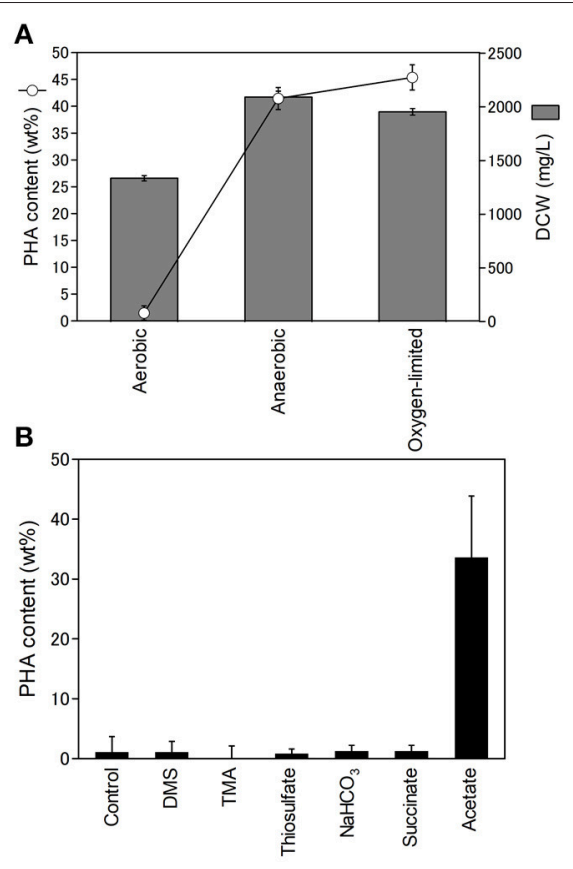

FIGURE 3 | Effect of oxygen concentration on cell growth and PHA production. (A) PHA content (open circles) and DCW (gray bars) under different oxygen conditions. Cells were cultured under aerobic, anaerobic and oxygen-limited conditions. (B) Effects of reductants and carbon sources on PHA production under aerobic conditions. Cells were cultured under aerobic conditions in the presence of $0.3 \%$ malate and $0.3 \%$ pyruvate supplemented with $10 \mathrm{mM}$ DMA (dimethylamine), $10 \mathrm{mM}$ TMA (trimethylamine) and $10 \mathrm{mM}$ thiosulfate as reductants and $20 \mathrm{mM}$ sodium bicarbonate, $0.5 \%$ sodium succinate and $0.5 \%$ sodium acetate as carbon sources. Data are the mean \pm SD of at least three cultures.

during growth. Some species, including Alcaligenes latus, mutant strains of Azotobacter vinelandii (Bormann et al., 1998) and recombinant E. coli strains (Slater et al., 1988), belong to the second group. The results of the present study indicate that marine purple non-sulfur bacteria belong to the second group, which do not require nutrient limitation for PHA accumulation. In the second group of bacteria, high PHA production at high cell densities leads to high PHA concentrations. As shown in Figure 2C, both PHA content and DCW reached saturation over 4 days of cultivation. Therefore, cultivation time is important for obtaining high PHA concentrations as well as for cell growth. The PHA productivity $(\mathrm{mg} / \mathrm{L} / \mathrm{h})$ was calculated under all the conditions to determine the optimal incubation time (Figure 2D). The PHA productivity was highest after 3 days of cultivation under low-light conditions with 800-nm LED lighting. The relationship between PHA productivity and time of cultivation was analyzed under different light intensities. We found a negative correlation $\left(R^{2}=0.523\right)$ under high light conditions although no relationship was observed under low light conditions $\left(R^{2}=0.180\right)$. These results suggest that prolonged cultivation resulted in decreased productivity, although low-light conditions with 730-nm LED lighting seem to be the exception. Further optimization of light intensity and cultivation time is required to attain increased PHA production in marine purple non-sulfur bacteria.

\section{PHA Production Under Aerobic Conditions}

Purple non-sulfur bacteria are known to be able to grow heterotrophically in the dark under aerobic conditions. Next, we examined the effect of oxygen on PHA production. The PHA content and DCW of $R$. sulfidophilum were determined using cells grown under aerobic conditions in the dark, anaerobic conditions and oxygen-limited conditions in the light (Figure 3A). The DCW was highest under anaerobic conditions and lowest under aerobic conditions. We found that $R$. sulfidophilum cells accumulated very little PHA under aerobic conditions. R. imhoffii and R. visakhapatnamense also produced only $0.4 \mathrm{wt} \%$ and $1.8 \mathrm{wt} \%$ PHA, respectively, when cultured under aerobic conditions.

PHA is considered to be a store of reducing equivalents in addition to carbon. Therefore, the effects of additional reductants (DMS (dimethyl sulfide), TMA (trimethylamine), and thiosulfate) on PHA production were investigated under aerobic conditions. The addition of the three reductants did not affect PHA production under aerobic conditions (Figure 3B), suggesting that reducing equivalents are not key factors affecting PHA production under aerobic conditions. In the growth medium, malate and pyruvate were used as carbon sources. PHA production under aerobic conditions was also evaluated by the addition of three carbon sources (sodium bicarbonate, sodium succinate, and sodium acetate). The addition of sodium bicarbonate and succinate did not affect PHA production. Interestingly, $R$. sulfidophilum produced 33\% PHA upon the addition of acetate under aerobic conditions (Figure 3B). These results indicate that the acetate-dependent pathway is important for PHA production under aerobic conditions. PHA production in the presence of reductants or carbon sources was also examined under anaerobic conditions (Figure S3). There were no noticeable changes upon the addition of TMA, DMS, and acetate under anaerobic conditions, suggesting that reducing equivalents and the acetate-dependent pathway are not involved in PHA production under anaerobic conditions.

\section{Expression Levels of TCA Cycle Enzymes}

To identify the gene involved in PHA production under aerobic and anaerobic conditions, gene expression levels were analyzed by quantitative RT-PCR. PhaC (PHA synthase), $P D H$ (pyruvate dehydrogenase), ACS (acetyl CoA synthase), and $I D H$ (isocitrate dehydrogenase) were selected for gene expression analysis (Figure 4A). PhaC is a key enzyme of the PHA biosynthesis pathway and polymerizes the PHA monomer. $\mathrm{PDH}$ catalyzes the conversion of pyruvate to acetyl CoA. ACS catalyzes the ligation of acetate and CoA to form acetyl CoA. The expression levels of $P D H, p h a C$, and ACS were not significantly different between aerobic and anaerobic conditions (Figure 4B). Intriguingly, the expression level of $I D H$ was lower under aerobic conditions than under anaerobic conditions. IDH catalyzes the oxidative decarboxylation of isocitrate to $\beta$ ketoglutarate and is an important enzyme in the TCA cycle. These results suggest that the TCA cycle activity decreased 
A

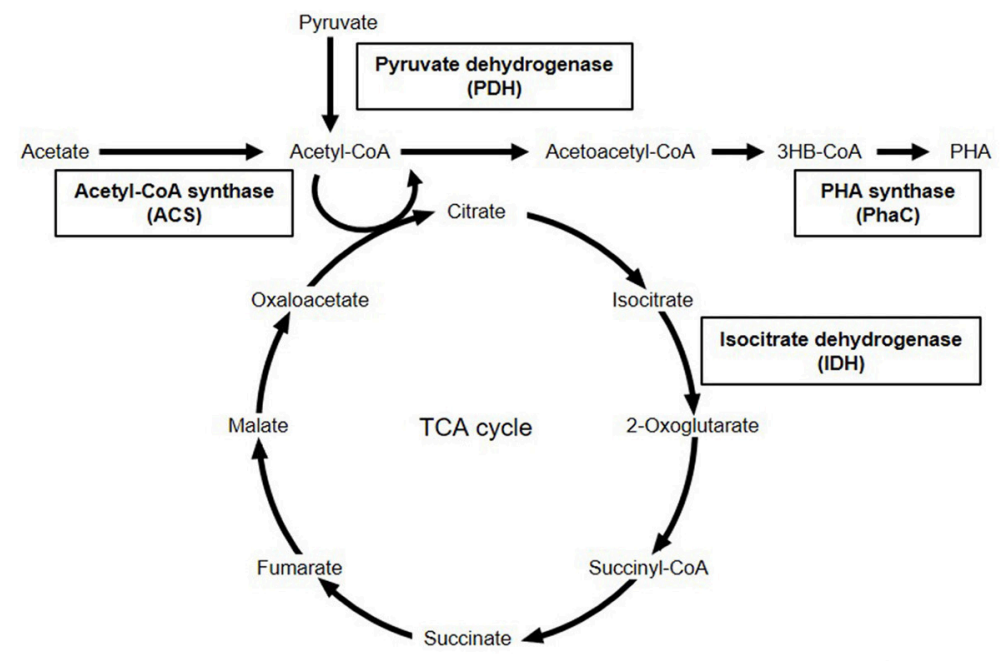

B

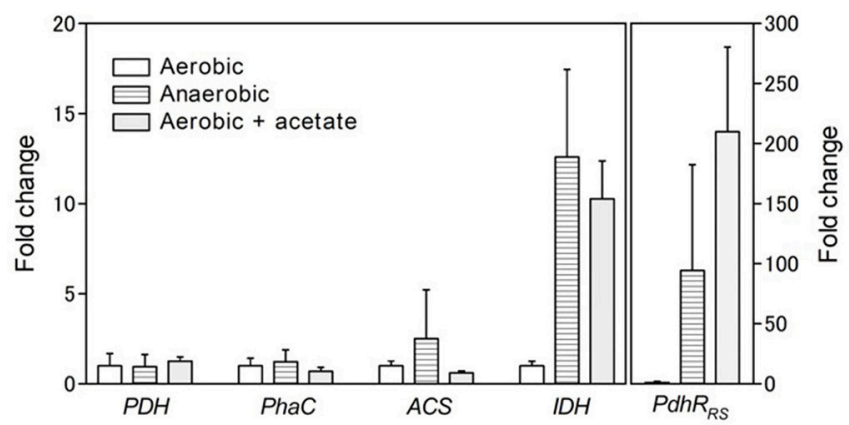

C

FIGURE 4 | Gene expression analysis. (A) Schematic representation of carbon metabolic pathway. (B) Gene expression analysis of selected genes under aerobic conditions with or without acetate and anaerobic conditions. The expression levels are shown as the relative values compared with those of cells grown aerobically. The rpoD gene was used as a housekeeping gene to normalize the expression levels of target genes. (C) Gene expression analysis under different light conditions. Cells were cultured in low (light gray bars; $8 \mathrm{~W} / \mathrm{m}^{2}: 800 \mathrm{~nm}$ ) and high (dark gray bars; $50 \mathrm{~W} / \mathrm{m}^{2}: 800 \mathrm{~nm}$ ) light for 3 days. Data are the mean $\pm \mathrm{SD}$ from at least three cultures. ${ }^{\star} P<0.05$.

under aerobic conditions. Low PHA production under aerobic conditions might be caused by low activity of the TCA cycle. Low PHA accumulation in the presence of malate and succinate under aerobic conditions (Figure 3B) is plausible because these metabolites are intermediates of the TCA cycle.

\section{Effect of Acetate Addition}

We also evaluated the effect of the addition of acetate on $I D H$ expression. The IDH expression level increased 10-fold in the presence of acetate under aerobic conditions (Figure 4B). This finding suggests that the TCA cycle activity was enhanced by the addition of acetate under aerobic conditions. Recently, proteome analysis was carried out to investigate the metabolism of acetate under aerobic conditions in R. rubrum (Narancic et al., 2016). The results of the present study are consistent with the finding that the expression of succinate dehydrogenase in the TCA cycle was slightly increased by the addition of acetate. The TCA cycle is known to be regulated at two levels: the conversion of pyruvate into acetyl CoA, which is catalyzed by $\mathrm{PDH}$, and the entry of acetyl CoA into the TCA cycle, which is catalyzed by citrate synthase. Acetyl CoA can be formed directly from acetate without the regulation of the TCA cycle when exogeneous acetate is supplied to the cells. PHA accumulation and enhancement of the TCA cycle by the addition of acetate might be explained by the direct production of acetyl CoA from acetate. Alternatively, the ethylmalonyl-CoA (EMC) pathway has been characterized as an acetate assimilation pathway in $R$. sphaeroides (Erb et al., 2007). In the EMC pathway, acetate is transformed to the TCA cycle intermediates L-malate and succinyl-CoA. The betaketothiolase (PhaA) and acetoacetyl-CoA reductase $(\mathrm{PhaB})$ in the PHA biosynthesis pathway are shared with the EMC pathway. Therefore, induction of the EMC pathway by acetate would lead to the enhancement of PHA biosynthesis and the TCA cycle. The crotonyl-CoA carboxylase/reductase in the EMC pathway was identified in the genome of $R$. sulfidophilum. The EMC pathway activity might be enhanced by the addition of acetate in $R$. sulfidophilum, leading to PHA accumulation via the PhaAand $\mathrm{PhaB}$-catalyzed reactions.

IDH is regulated by the NADH/NAD ${ }^{+}$and ATP/ADP ratios (Chen and Plaut, 1963). PDH is also known to be regulated by the NADH/NAD ${ }^{+}$and ATP/ADP ratios and acetyl-CoA (Hansen and Henning, 1966; Shen and Atkinson, 1970; Luderitz 
and Klemme, 1977). Although the PDH mRNA levels did not change with the addition of acetate (Figure 4B), PDH protein expression was shown to be decreased by the addition of acetate in $R$. rubrum (Narancic et al., 2016). PDH regulation is reported to be controlled by PdhR (pyruvate dehydrogenase complex regulator) in some bacteria (Quail et al., 1994). PdhR is a member of the GntR family of transcription factors. The GntR family is widely distributed in bacteria and shown to be involved in sensing cellular signals in response to carbon utilization (Hillerich and Westpheling, 2006). A search for homologous amino acid sequences against $R$. sulfidophilum was performed using PdhR from E. coli, and a PdhR homolog was found in R. sulfidophilum $\left(\mathrm{Pdh}_{\mathrm{Rs}}\right.$ ). $\mathrm{Pdh} \mathrm{R}_{\mathrm{Rs}}$ is composed of 256 amino acid residues and is conserved in $R$. rubrum and $R$. sphaeroides (Figure S4). The expression levels of $P d h R_{R s}$ were determined under three conditions. $P d h R_{R s}$ expression was highly enhanced (210-fold) by the addition of acetate under aerobic conditions (Figure 4C), suggesting that $P d h R_{R s}$ might be involved in the acetate-dependent pathway. The function of $\mathrm{PdhR}_{\mathrm{Rs}}$ and its role in PHA production are currently unknown. PdhR is proposed to function as a master regulator of genes involved in energy production (Ogasawara et al., 2007). PHA production and the TCA cycle might be regulated by $\mathrm{PdhR}_{\mathrm{Rs}}$ in R. sulfidophilum.

\section{Expression Analysis at Different Light Intensities}

Gene expression analysis was also carried out using $R$. sulfidophilum cells grown under low and high light intensities with 800-nm LED lighting (Figure 4C). The expression levels of $I D H$ and $P h a C$ were almost the same between the different light intensities. The gene expression levels of other PHA biosynthesis genes, namely, PhaP (PHA granule associated protein) and PhaZ (PHA depolymerase), were also approximately the same under the two different light intensities. These results suggest that low PHA accumulation under high-light conditions was not explained by changes in the TCA cycle and the PHA biosynthesis pathway. PDH expression under high-light conditions was only slightly higher compared to low-light conditions. A more than 3-fold increase in the expression level under high-light conditions was observed for $P d h R_{R s}$, suggesting that $\mathrm{PdhR}_{\mathrm{Rs}}$ might be involved in PHA production under highlight conditions.

Under high-light conditions, purple non-sulfur bacteria must dissipate excess reducing power to protect cells from photooxidative damage. PHA is considered to serve as an electron sink because PhaB uses NADH as a cofactor. However, PHA production under high-light conditions was lower than that under low-light conditions, as shown in Figure 2. Therefore, another pathway that dissipates reducing power must be enhanced under high-light conditions. It has been reported that hydrogen production catalyzed by nitrogenase increased under high-light conditions in Rhodopseudomonas palustris (Muzziotti et al., 2016), and PHA synthesis is considered to compete with hydrogen production in terms of utilization of reducing power (DePhilippis et al., 1992). Another possible pathway is the
Calvin cycle, which requires reducing power. RuBisCO, which is an important enzyme in the Calvin cycle, is proposed to control the redox potential in R. rubrum, and PHA synthesis affected RuBisCO activity (Narancic et al., 2016). Hydrogen production and/or $\mathrm{CO}_{2}$ fixation might be induced under highlight conditions to dissipate excess reducing power. Further investigation is needed to elucidate the mechanism.

\section{CONCLUSION}

In this study, we characterized PHA production in marine purple non-sulfur bacteria under various culture growth conditions (nutrient limitations, oxygen levels and light intensities and qualities). Marine purple non-sulfur bacteria could accumulate PHA during growth, and nutrient limitation did not lead to high PHA concentrations ( $\mathrm{mg} / \mathrm{L}$ of culture) unlike the well-studied PHA-producing bacteria. Low PHA production under aerobic conditions was caused by low TCA cycle activity and PHA production was strongly induced by the addition of acetate. Gene expression analysis revealed that the GntR family transcription factor PdhR (pyruvate dehydrogenase complex regulator) might have a role in the changes in the metabolic state.

\section{DATA AVAILABILITY}

The raw data supporting the conclusions of this manuscript will be made available by the authors, without undue reservation, to any qualified researcher.

\section{AUTHOR CONTRIBUTIONS}

$\mathrm{KN}$ conceptualized the study and planned various experiments. $\mathrm{MH}-\mathrm{T}$ planned and performed various experiments. $\mathrm{KN}$ and $\mathrm{MH}-\mathrm{T}$ wrote the manuscript.

\section{FUNDING}

This work was supported by JSPS KAKENHI grant number JP16K00593, JST ERATO grant number JPMJER1602, the Impulsing Paradigm Change through the Disruptive Technologies Program (ImPACT) and the Institute for Fermentation.

\section{ACKNOWLEDGMENTS}

We thank the RIKEN BioResource Center, Leibniz Institute DSMZ-German Collection of Microorganisms and Cell Cultures (DSMZ) and Global Bioresource Center (ATCC) for providing the photosynthetic purple bacteria strains.

\section{SUPPLEMENTARY MATERIAL}

The Supplementary Material for this article can be found online at: https://www.frontiersin.org/articles/10.3389/fbioe. 2019.00118/full\#supplementary-material 


\section{REFERENCES}

Akiyama, M., Tsuge, T., and Doi, Y. (2003). Environmental life cycle comparison of polyhydroxyalkanoates produced from renewable carbon resources by bacterial fermentation. Poly. Degrad. Stabil. 80, 183-194. doi: 10.1016/S0141-3910(02)00400-7

Bormann, E. J., Leissner, M., and Beer, B. (1998). Growth-associated production of poly(hydroxybutyric acid) by Azotobacter beijerinckii from organic nitrogen substrates. Appl. Microbiol. Biotechnol. 49, 84-88. doi: 10.1007/s0025300 51141

Brandl, H., Lenz, R. W., Lloyd, R., and Fuller, R. C. (1991). The accumulation of poly(3-hydroxyalkanoates) in Rhodobacter sphaeroides. Arch. Microbiol. $155,337-340$.

Chen, R. F., and Plaut, G. W. (1963). Activation and inhibition of Dpn-linked isocitrate dehydrogenase of heart by certain nucleotides. Biochemistry 2, 1023-1032.

Choi, J., and Lee, S. Y. (1999). Factors affecting the economics of polyhydroxyalkanoate production by bacterial fermentation. Appl. Microbiol. Biotechnol. 51, 13-21. doi: 10.1007/s002530051357

Chowdhury, W. Q., Idehara, K., Maeda, I., Umeda, F., Yagi, K., Miura, Y., et al. (1996). Factors affecting polyhydroxybutyrate biosynthesis in the marine photosynthetic bacterium Rhodopseudomonas sp strain W-1S. Appl. Biochem. Biotechnol. 57/58, 361-366. doi: 10.1007/978-1-4612-0223-3_31

Chuah, J. A., Yamada, M., Taguchi, S., Sudesh, K., Doi, Y., and Numata, K. (2013). Biosynthesis and characterization of polyhydroxyalkanoate containing 5-hydroxyvalerate units: Effects of 5HV units on biodegradability, cytotoxicity, mechanical and thermal properties. Poly. Degrad. Stabil. 98, 331-338. doi: 10.1016/j.polymdegradstab.2012.09.008

Clemente, T., Shah, D., Tran, M., Stark, D., Padgette, S., Dennis, D., et al. (2000). Sequence of PHA synthase gene from two strains of Rhodospirillum rubrum and in vivo substrate specificity of four PHA synthases across two heterologous expression systems. Appl. Microbiol. Biotechnol. 53, 420-429. doi: 10.1007/s002530051636

DePhilippis, R., Ena, A., Guastiini, M., Sili, C., and Vincenzini (1992). Factors affecting poly- $\beta$-hydroxybutyrate accumulation in cyanobacteria and in purple non-sulfur bacteria. FEMS Microbiol. Rev. 103, 187-194.

Erb, T. J., Berg, I. A., Brecht, V., Muller, M., Fuchs, G., and Alber, B. E. (2007). Synthesis Of $\mathrm{C}_{5}$-dicarboxylic acids from $\mathrm{C}_{2}$-units involving crotonyl-CoA carboxylase/reductase: The ethylmalonyl-CoA pathway. Proc. Nat. Acad. Sci. USA. 104, 10631-10636. doi: 10.1073/pnas.0702791104

Hansen, R. G., and Henning, U. (1966). Regulation of pyruvate dehydrogenase activity in Escherichia coli K12. Biochimica. Et. Biophysica. Acta. 122, 355-358. doi: 10.1016/0926-6593(66)90076-2

Higuchi-Takeuchi, M., Morisaki, K., Toyooka, K., and Numata, K. (2016). Synthesis of high-molecular-weight polyhydroxyalkanoates by marine photosynthetic purple bacteria. PLOS ONE 11:e0160981. doi: 10.1371/journal.pone.0160981

Higuchi-Takeuchi, M., Motoda, Y., Kigawa, T., and Numata, K. (2017). Class I polyhydroxyalkanoate synthase from the purple photosynthetic bacterium Rhodovulum sulfidophilum predominantly exists as a functional dimer in the absence of a substrate. ACS Omega 2, 5071-5078. doi: 10.1021/acsomega.7b00667

Hillerich, B., and Westpheling, J. (2006). A new GntR family transcriptional regulator in Streptomyces coelicolor is required for morphogenesis and antibiotic production and controls transcription of an $\mathrm{ABC}$ transporter in response to carbon source. J. Bacteriol. 188, 7477-7487. doi: 10.1128/Jb.00898-06

Idi, A., Nor, M. H. M., Wahab, M. F. A., and Ibrahim, Z. (2015). Photosynthetic bacteria: an eco-friendly and cheap tool for bioremediation. Rev. Environ. Sci. Bio-Technol. 14, 271-285. doi: 10.1007/s11157-014-9355-1

Joshi, H. M., and Tabita, F. R. (1996). A global two component signal transduction system that integrates the control of photosynthesis, carbon dioxide assimilation, and nitrogen fixation. Proc. Nat. Acad. Sci. U.S.A. 93, 14515-14520. doi: 10.1073/pnas.93.25.14515

Lee, S. Y. (1996a). Bacterial polyhydroxyalkanoates. Biotechnol. Bioeng. 49, 1-14. doi: 10.1002/(SICI) 1097-0290(19960105)49:1<1::AID-BIT1> 3.0.CO;2-P
Lee, S. Y. (1996b). Plastic bacteria? Progress and prospects for polyhydroxyalkanoate production in bacteria. Trends Biotechnol. 14, 431-438. doi: 10.1016/0167-7799(96)10061-5

Levin, D. B., Pitt, L., and Love, M. (2004). Biohydrogen production: prospects and limitations to practical application. Int. J. Hydro. Energy 29, 173-185. doi: 10.1016/S0360-3199(03)00094-6

Liebergesell, M., Hustede, E., Timm, A., Steinbuchel, A., Fuller, R. C., Lenz, R. W., et al. (1991). Formation of poly(3-hydroxyalkanoates) by phototrophic and chemolithotrophic bacteria. Arch Microbiol. 155, 415-421. doi: 10.1007/BF00244955

Luderitz, R., and Klemme, J. H. (1977). Isolation and characterization of a membrane-bound pyruvate-dehydrogenase complex from phototropic bacterium Rhodospirillum rubrum. Zeitschrift Fur Naturforschung C-a J Biosci. $32,351-361$.

Martina, M., and Hutmacher, D. W. (2007). Biodegradable polymers applied in tissue engineering research: a review. Poly. Int. 56, 145-157. doi: $10.1002 /$ pi.2108

Masuda, S., Matsumoto, Y., Nagashima, K. V., Shimada, K., Inoue, K., Bauer, C. E., et al. (1999). Structural and functional analyses of photosynthetic regulatory genes regA and regB from Rhodovulum sulfidophilum, Roseobacter denitrificans, and Rhodobacter capsulatus. J. Bacteriol. 181, 4205-4215.

McKinlay, J. B., and Harwood, C. S. (2010). Photobiological production of hydrogen gas as a biofuel. Curr. Opin. Biotechnolo. 21, 244-251. doi: 10.1016/j.copbio.2010.02.012

Mittendorf, V., Robertson, E. J., Leech, R. M., Kruger, N., Steinbuchel, A., and Poirier, Y. (1998). Synthesis of medium-chain-length polyhydroxyalkanoates in Arabidopsis thaliana using intermediates of peroxisomal fatty acid $\beta$-oxidation. Proc. Nat. Acad. Sci. U.S.A. 95, 13397-13402. doi: 10.1073/pnas.95.23. 13397

Mooney, B. P. (2009). The second green revolution? Production of plant-based biodegradable plastics. Biochem. J. 418, 219-232. doi: 10.1042/BJ2001769

Muzziotti, D., Adessi, A., Faraloni, C., Torzillo, G., and De Philippis, R. (2016). $\mathrm{H}_{2}$ production in Rhodopseudomonas palustris as a way to cope with high light intensities. Res. Microbiol. 167, 350-356. doi: 10.1016/j.resmic.2016. 02.003

Nakada, E., Asada, Y., Arai, T., and Miyake, J. (1995). Light penetration into cellsuspensions of photosynthetic bacteria and relation to hydrogen-production. J. Ferment. Bioeng. 80, 53-57. doi: 10.1016/0922-338x(95)98176-L

Narancic, T., Scollica, E., Kenny, S. T., Gibbons, H., Carr, E., Brennan, L., et al. (2016). Understanding the physiological roles of polyhydroxybutyrate (PHB) in Rhodospirillum rubrum S1 under aerobic chemoheterotrophic conditions. Appl. Microbiol. Biotechnol. 100, 8901-8912. doi: 10.1007/s00253-016-7711-5

Nomura, C. T., and Taguchi, S. (2007). PHA synthase engineering toward superbiocatalysts for custom-made biopolymers. Appl. Microbiol. Biotechnol. 73, 969-979. doi: 10.1007/s00253-006-0566-4

Ogasawara, H., Ishida, Y., Yamada, K., Yamamoto, K., and Ishihama, A. (2007). PdhR (pyruvate dehydrogenase complex regulator) controls the respiratory electron transport system in Escherichia coli. J. Bacteriol. 189, 5534-5541. doi: $10.1128 / \mathrm{Jb} .00229-07$

Osanai, T., Numata, K., Oikawa, A., Kuwahara, A., Iijima, H., Doi, Y., et al. (2013). Increased bioplastic production with an RNA polymerase sigma factor SigE during nitrogen starvation in Synechocystis sp. PCC 6803. DNA Res. 20, 525-535. doi: 10.1093/dnares/dst028

Quail, M. A., Haydon, D. J., and Guest, J. R. (1994). The pdhR-aceEF-lpd operon of Escherichia coli expresses the pyruvate dehydrogenase complex. Mol. Microbiol. 12, 95-104.

Rehm, B. H. (2003). Polyester synthases: natural catalysts for plastics. Biochem. J. 376(Pt 1), 15-33. doi: 10.1042/BJ20031254

Sasikala, C., and Ramana, C. V. (1995). Biotechnological potentials of anoxygenic phototrophic bacteria. 1. Production of single-cell protein, vitamins, ubiquinones, hormones, and enzymes and use in waste treatment. Adv. Appl. Microbiol. 41, 173-226. doi: 10.1016/S0065-2164(08)70310-1

Shen, L. C., and Atkinson, D. E. (1970). Regulation of pyruvate dehydrogenase from Escherichia coli - Interactions of adenylate energy charge and other regulatory parameters. J. Biol. Chem. 245, 5974-5978.

Slater, S. C., Voige, W. H., and Dennis, D. E. (1988). Cloning and expression in Escherichia coli of the Alcaligenes eutrophus H16 Poly-ïc- 
hydroxybutyrate biosynthetic-pathway. J. Bacteriol. 170, 4431-4436. doi: 10.1128/jb.170.10.4431-4436.1988

Tabita, F. R. (1995). The Biochemistry and Molecular Regulation of Carbon Metabolism and $\mathrm{CO}_{2}$ Fixation in Purple Bacteria. Anoxygenic photosynthetic bacteria, Madigan MT, Bauer CE, eds. Kluwer: Dordrecht Blankenship RE, 885-914.

Valappil, S. P., Rai, R., Bucke, C., and Roy, I. (2008). Polyhydroxyalkanoate biosynthesis in Bacillus cereus SPV under varied limiting conditions and an insight into the biosynthetic genes involved. J. Appl. Microbiol. 104, 1624-1635. doi: 10.1111/j.1365-2672.2007. 303678.x
Conflict of Interest Statement: The authors declare that the research was conducted in the absence of any commercial or financial relationships that could be construed as a potential conflict of interest.

Copyright (๑) 2019 Higuchi-Takeuchi and Numata. This is an open-access article distributed under the terms of the Creative Commons Attribution License (CC BY). The use, distribution or reproduction in other forums is permitted, provided the original author(s) and the copyright owner(s) are credited and that the original publication in this journal is cited, in accordance with accepted academic practice. No use, distribution or reproduction is permitted which does not comply with these terms. 